See discussions, stats, and author profiles for this publication at: https://www.researchgate.net/publication/331662889

\title{
Investigating retail property market dynamics through spatial accessibility
} measures

Article in Journal of European Real Estate Research · March 2019

DOI: 10.1108/JERER-01-2018-0009

CITATIONS

0

3 authors:

Adejimi Adebayo

Nottingham Trent University

9 PUBLICATIONS 3 CITATIONS

SEE PROFILE

0

Kevin Muldoon-Smith

Northumbria University

23 PUBLICATIONS 35 CITATIONS

SEE PROFILE

Some of the authors of this publication are also working on these related projects:

Project $\quad$ Future Cities View project

Future of city retail space View project
READS

36

Paul Greenhalgh

Northumbria University

40 PUBLICATIONS 153 CITATIONS

SEE PROFILE 


\section{Northumbria Research Link}

Citation: Adebayo, Jimi, Greenhalgh, Paul and Muldoon-Smith, Kevin (2019) Investigating Retail Property Market Dynamics through Spatial Accessibility Measures. Journal of European Real Estate Research. ISSN 1753-9269 (In Press)

Published by: Emerald

URL: https://doi.org/10.1108/JERER-01-2018-0009 <https://doi.org/10.1108/JERER-012018-0009>

This version was downloaded from Northumbria Research Link: http://nrl.northumbria.ac.uk/37770/

Northumbria University has developed Northumbria Research Link (NRL) to enable users to access the University's research output. Copyright $\odot$ and moral rights for items on NRL are retained by the individual author(s) and/or other copyright owners. Single copies of full items can be reproduced, displayed or performed, and given to third parties in any format or medium for personal research or study, educational, or not-for-profit purposes without prior permission or charge, provided the authors, title and full bibliographic details are given, as well as a hyperlink and/or URL to the original metadata page. The content must not be changed in any way. Full items must not be sold commercially in any format or medium without formal permission of the copyright holder. The full policy is available online: http://nrl.northumbria.ac.uk/policies.html

This document may differ from the final, published version of the research and has been made available online in accordance with publisher policies. To read and/or cite from the published version of the research, please visit the publisher's website (a subscription may be required.) 


\section{Investigating Retail Property Market Dynamics through Spatial Accessibility Measures}

\section{Abstract}

Purpose: The retail property market is constantly adapting to the continuous demand of retailers and their consumers. This research project investigates retail property market dynamics through spatial accessibility measures of York's street network. It explores how Spatial Accessibility Metrics (SAM) explain Retail Market Dynamic (RMD) through changes in the city’s retail rental values and stock.

Methodology/Approach: Valuation Office Agency (VOA) datasets (aspatial) and Ordnance Survey Maps (spatial) form the empirical foundation for this investigation. Changes in retail rental value and stock between 2010 and 2017 of VOA datasets (valuation summary lists) represented the RMD variables. While, the configured street network measures of space syntax, namely, global integration, local integration, global choice and Normalised Angular Choice (NACH) were utilised as the SAM variables. The relationship between these variables were analysed through geo-visualization and statistical testing using QGIS and SPSS tools.

Findings: The study reveals that there has been an overall negative changes of $15 \%$ and $22 \%$ in rental value and retail stock respectively, even though some locations within the sampled city (York, North Yorkshire, England) indicated positive changes. The study further indicated that changes in retail rental value and stock have occurred within locations with good accessibility index. It also verifies that there are spatial and statistical relationship between variables and 22\% of RMD variability was jointly accounted for by SAM.

Originality/Value: This research is the first to investigate changes in retail property market variables through spatial accessibility measures of space syntax. It contributes to the burgeoning research field of Space Syntax and real estate.

Keywords: retail property market, rental value changes, retail stock changes, space syntax, street network and spatial accessibility metrics. 


\subsection{Introduction}

Retail activity remains one of the predominant functions of UK cities and prevailing land use of city and town centres. It involves recurrent transactions between two main market participants, namely, retailer and consumer, in order to effect trade. The mode of transaction between retailers and consumers continue to change as result of technological advancement, government policies and other socio-economic factors (Rhodes and Brien, 2017). Consequently, retail property markets performance indicators such as, rental value, vacancy, availability, absorption rates, stock and others continue to be volatile (Vitalii and Lena, 2016). Perhaps, what will remain unchanged about retailing (in-store) is that street network will remain the connecting links through which consumer reaches retailer to effect trade on retail space (Adebayo et. al., 2017). Thus, connectivity of streets (i.e. spatial accessibility) remains crucial to both retailers and consumers whilst selecting and visiting retail property respectively. Preliminary studies have adopted various strategies and developed models to explain changes in commercial property market for various cities (Barras, 1994; Nanthakumara et. al., 2000; Hendershott et. al., 2002; Dunse et. al., 2010; Liang and Wilhelmsson, 2011; Astbury \& Godwin, 2014). Likewise, relating studies (Tsolacos and Mcgough, 1999; Ingrid, 2006; Greenhalgh, 2008; Nsibande and Boshoff, 2017) have also contributed to the understanding of how changes in property market performance indicators influence spatial decisions of market actors on development, investment and occupation of commercial property. These preceding studies have provided insights as to how changes in retail property market variables influence demand and supply of retail property within cities. However, the only tangible means through which consumers will always connect and access retail property (i.e. street network) has never been considered in the previous works. This important gap requires exigent consideration for optimum utilisation of city (retail) space as online retailing and other factors are changing the 
structure of retail markets, which are currently characterised by declining retail stores and increasing vacant stock among other concerning conditions (Deloitte, 2018).

This novel study took up the challenge of investigating retail property market dynamics through spatial accessibility measures of a city street network. It measures the spatial accessibility index of street network for a sampled city using space syntax's theory to compute the suppose retail consumer movement pattern on a city network. It explores and investigates how spatial accessibility metrics explain and relate with changes in retail property market indicators within a sampled UK city network.

\subsection{Background}

\subsection{Concepts and factors influencing performance (changes) of Retail Property Markets.}

The influence of retail consumers on retail market actors' decisions can be overwhelming. This is because both user and investment markets (demand) for a retail property (space) is a function of the retail consumer demand for retail goods and services (Brown, 1991; Colwell and Jackson, 2004). It is the collective individual choices of consumers that form the basis of the retail property market performance. Ordinarily, retailers (i.e. retail space occupiers) will consider latent patronage ability of retail consumers for goods and services in a local market before demanding to occupy and use the property (space) for retail purpose. Similarly, an investor will seeks to invest in retail property space on the expectation that there is occupier demand for retail space with concurrent low supply of retail space in that location (Colwell and Jackson, 2004). In other words, retail consumers' demands for retail products influence decisions of user and investment retail property markets on what, where and whether to develop, invest-in and occupy a retail property (space). Considering the significance of consumer demand on retail property market performance, it is pertinent that consumer movement actions on retail space should be considered when estimating locational performance for key market decision making on development, investment and occupation of 
retail property. Retail property market performance on a spatial layout are measurable through the changes in market indicators (namely, rent and stock) over certain periods where noticeable market changes on that indicator is expected to have occurred (Adebayo et al., 2017). Changes in any of the market indicators are expected to indicate positive, negative or neutral (no change) performance of the property market within a given spatial layout. These directional changes are useful information dashboards in making market decisions on development, investment and occupation of retail spaces.

The retail market remains one of the most dynamic property markets due to it high dependence on consumers' decisions. Retail activities continue to change because of various factors influencing retail consumers and retail market performance indicators. These factors influence the market performance (including, demand of retail products and demand and supply of retail space) across any given spatial layouts (Dixon, 2007; Evans; 2008). Wyatt (1996) categorised factors influencing property performance into external and internal factors. The external factors include location (access) and overall economic performance of the property, while the internal factors include all legal (lease terms) factors and physical attributes (such as, floor sizes, building specifications among others) as shown in Figure 1.

Besides the revealed factors in Figure 1, there are other factors such as technology (online retailing), planning policies, retailers' branding and strategies that may influence retail market indicators. However, external factors, namely, economy, location and accessibility have been identified as the main influencing factor on the retail property market performance (Rhodes and Brien, 2017). This is because these external factors influence retail consumer patronage (including, movement and expenditure) and overall retail market performance (Huff, 1962; Brown, 2006; Rhodes and Brien, 2017). An instance of external (economic) factor is the global economic recession of 2008 that had significant negative impacts (such as, increase vacancy rates, reductions in net rents, increases void periods, reductions in capital values among others) 
on retail consumer patronage (expenditure) and the overall UK property market (Astbury \& Godwin, 2014; ONS, 2017). On the other hand, the internal factors are more property-specific elements that are indefinable and do not reflect the overall market performance (Wyatt, 1996; Brown, 2006; Astbury and Godwin, 2014). For example, building specification is of relatively less importance to retail consumers and overall market performance when compared to location and accessibility (Wyatt, 1996; RICS, 2017).

The pattern of city spatial network helps to shape retail consumer movement, which in turn plays a role in determining the distribution of retailers (stock) and performance of rental value on city space. Huff (1962) explained that accessibility distribution scores of retail space (stores) could influence retail consumers' movement patterns. He emphasised that retail spaces located on good accessible links perform better than retail spaces with poor accessible link in terms of footfall, vibrancy, rental value and demand of space. However, the extents to which accessibility index, that is, consumer movement pattern on city (retail) space will influence performance of market indicators such as rent (value) and stock is relatively unknown.

\subsection{Concept of Spatial Accessibility Measurement (SAM)}

It can be argued that accessibility index of locations within a given street network will determine retail consumer movement pattern on that city space (Huff, 1962). The concept of accessibility measurement within a city space network can generally be categorised into functional accessibility and spatial accessibility (Guers \& van Wee, 2004; Reggiani, 2014; Jie et. al., 2017). The functional accessibility measurement involves estimating relative ease of movement from origin ' $\mathrm{O}$ ' to a destination ' $\mathrm{D}$ ' while taking into consideration deterrence factors such as, costs of movement, time spent on movement and the distance travelled (Reggiani, 2014; Jie et. al., 2017). However, the spatial accessibility measurement solely determines the relative connectedness of places (streets) within the city spaces in relation to other places. Hence, spatial accessibility measurement does not concern itself with deterrence 
factors, but the interconnectivity pattern of streets whilst evaluating location accessibility within a city network (Baradaran \& Ramjerdi, 2001; Litman, 2003). Space syntax ideologies adhere to the principles of spatial accessibility, and its configuration outputs, namely, integration and choice metrics, have been respectively identified as to-movement and throughmovement potential of people within a given street network (Hillier \& Hanson, 1984).

Space syntax explicitly computes accessibility indexes for streets network through spatial configuration without considering the socio-economic activities on the same city space (Batty, 2008; Giannopoulou et al., 2016). However, studies have revealed that configured outputs (i.e. assigned syntactic values of street network) correlate and explain some socio-economic variables, such as, property values (Chiaradia et. al, 2009; Law et al, 2013; Muldoon-Smith et al., 2015), pedestrian and vehicular movement pattern (Hillier, 1996, Peponis et al., 1997) and pattern of land use distributions (Stonor, 2013) within cities. Conversely, there have been disparities amongst scholars’ findings, especially the relationship between spatial configuration outputs and property values. For example, Muldoon-Smith et. al. (2015) revealed that the values of commercial property (namely, retail, offices and industrial) relate differently with integration outputs for City of Leeds. Similarly, Giannopoulou et. al. (2016) while investigating Xanthi city in Greece revealed there were negative relationships between configured integration metrics and the residential property values of the city. Meanwhile, Chiaradia et. al. (2009) investigated a suburb area in London, and revealed there were positive relationships between the residential property values and the configured outputs of choice and integration metrics. However, a common shortcoming to all the aforementioned studies (Chiaradia et. al., 2009; Muldoon-Smith et al., 2015 and Giannopoulou et al., 2016) is that the relationship tests on variables do not consider the statistical significance of spatial configuration outputs (variables) on the property values variable. It can be contended that this unexplored relationships could shed new light on the statistical outputs in these studies. In other words, the 
uniqueness in property market characteristics and spatial structures of the aforementioned cities could have led to variations in results.

This research deficit provides the motivation for investigating how spatial accessibility measures (namely, choice and integration metrics) explain the changes in retail rental value and stock within a city street network. The study explores how specific spatial accessibility index (namely, integration and choice metrics at local and global scales) influence changes in retail rental value and supply stock within City of York's street network. Geo-spatial and statistical relationships between retail market indicators (changes in rent and stock) and spatial accessibility index (measures of 'to' and 'through' movement) variables were explored. This is important in establishing reliable location performance of city (retail) space for optimum decision making on occupation, investment and development of retail space.

\subsection{Spatial Configuration of City Streets Network through Segment Map Analysis}

The theory of space syntax uses graph analysis techniques to measure accessibility index of spaces (including, cities and buildings) through spatial configurations (Peponis et al., 1997; Figueirodo, 2015). Spatial configuration of a given city street network is conducted using segment map analysis to assign syntactic values to spaces (or streets) by analysing complex relations between streets (while taking into account all other streets within the city network) (Hillier et al, 1993). Space syntax’s fundamental ideologies repose on the premise that human movements within street network follow a set of procedural rules and patterns (Hillier, 1993; Peponis et al., 2008). The procedural rule is that humans (groups of individuals) will navigate within a given street network while making the least angular turns (Hillier, 1993; Peponis et al., 2008). This ideology has been developed into computer algorithms to compute the supposed usage of a configured or designed space in terms of visibility and movement in an explicit manner (Peponis et al., 1997; Jeong \& Ban, 2011). 
Over the years, availability of big spatial data (especially road centre line) has encouraged urban (space syntax) analysts to adopt segment map analysis over hand drawn axial maps while analysing space at city scale level (Kolovou et. al., 2016). The segment map analysis allows users to analyse street networks at various controlled metric radii (i.e. local configuration analysis) in order to reflect various modes of human movement within a given city space (Jiang, 2008). Dalton \& Dalton (2007) revealed that high metric radii represent fast modes of transportations, e.g. vehicular movement, while some lower metric radii will indicate cycling or walking within the city street network. Peponis et. al. (2008) also indicated that 400m and 800m metric radii represent 5 minutes and 10 minutes' walk respectively within a given city street network. Hillier et. al. (2012) further explained that normalisation of configured metric variables (specifically, angular choice) can be carried out through segment map analysis within DepthMapX software tool. Hillier et. al. (2012) explicated that normalising angular choice can be done by dividing configured choice metric values with corresponding total-depth metric values in order to eliminate inconsistencies associated with variations in street network patterns.

This study proposes that the manner in which a given street network is configured will influence changes (positive and negative) in retail rental values and stock within a given city space. Hence, the following propositional statements are made and further tested:

$1^{\text {st }}$ proposition statement:

'the higher the accessibility indexes of streets (locations), the more the rental value changes, and vice versa'.

$2^{\text {nd }}$ proposition statement:

'the higher the accessibility indexes of streets (locations), the more the stock changes, and vice versa'. 


\subsection{Methodology}

\subsection{The study area.}

The street network of City of York in North Yorkshire, England has been chosen to pilot this experimental research. The city has rich heritage and longstanding built environment of iconic and listed buildings that annually attracts over 7 million tourists and visitors (as potential retail consumers), who spend more than $£ 400$ million on retailing (VisitYork, 2017).

The rationale behind studying York is due to the monocentric landscape of the city fabric and retail distribution pattern within the city network. York is perhaps one of the few monocentric UK cities that has no large purpose built shopping centre within its network. As such, excessive artificial control of retail property market (that is possible in shopping centres by landlords and managers) is almost impossible within City of York network. This allows for an undisrupted investigation into the city retail property market at a city network level. Similarly, the city is relatively well defined and small, both in land area, and the commercial (retail) property market size. Therefore, it is ideal to explore in order to pilot the developed research method.

\subsection{Sources of Data Variables}

Data utilised in this study have been broadly categorised into aspatial and spatial datasets. This is because the sources and processes taken in obtaining variables of aspatial and spatial data differ. Herein, the aspatial datasets are all forms of data that have been used as market indicators and were not obtained as map data. While, the spatial data have been obtained as map features data.

The aspatial datasets were obtained from valuation summary lists (2010 and 2017) of Valuation Office Agency (VOA). The VOA holds valuation summary lists (henceforth, VOA data) for all rateable commercial (including retail, offices and industrial) properties across England and Wales for taxation purposes. The rational for utilising VOA data in this study (that is based on property market analysis), is not limited to the data availability, completeness, relevance and 
comprehensiveness (Greenhalgh and Kings, 2013; Astbury \& Godwin, 2014). The recent public release of VOA datasets provides opportunity for understanding the actual changes that have occurred in commercial property market (variables) as against predicting it. The VOA data contain commercial (retail) market indicators useful in estimating market performance on any given cities locations within England and Wales. The VOA data holds rateable values (based on market rental values as at the date of valuation), floor areas, Unique Address Reference Number (UARN), occupiers, property uses, date of valuation and property addresses for all non-residential properties in England and Wales (VOA, 2017). It is important to note that the valuation dates for 2010 VOA data is April 2008, while the valuation date for 2017 VOA data is April 2015 (VOA, 2017). The rateable values at date of valuation (that is, market values) and floor areas of retail hereditaments ${ }^{1}$ within the City of York have been extracted from the list and utilised as retail rental values and stock respectively. The UARN feature serves as the common key that was utilised in matching records (features) of the same retail property in 2010 and 2017 data. As such, the actual locational changes in features can be established with high level of precision.

Consequently, the aspatial data variables, that is, changes in rental value and changes in stock for all (rateable) retail property within York were computed by subtracting 2010 market rent values (as at April 2008) from the 2017 market rent (as at April 2015). These variables are termed as Retail Market Dynamic (RMD) variables in this study. Hence, the computation formula of the RMD variables are thus:

$$
\begin{aligned}
& \mathrm{RMD}_{1}=2017 \text { rental value }-2010 \text { rental value } \\
& \mathrm{RMD}_{2}=2017 \text { stock }-2010 \text { stock }
\end{aligned}
$$

\footnotetext{
${ }^{1}$ Retail hereditaments are all rateable retail property (spaces) in the VOA data. Effectively, they represent units of property.
} 
Having established the RMD variables, a database was created for the aspatial (VOA) datasets using the MS Access tool, where relevant data variables (i.e. UARN, rateable value, address, floor area, occupier, date of valuation, property type and use) were arranged in columns. This table was then exported into MS Excel tool ${ }^{2}$ where additional columns were created for the RMD variables $^{3}$ and their corresponding geographical coordinates $^{4}$ (i.e. Eastings and Northings). The RMD variables were then populated for all the rows (i.e. retail property/hereditament) using the above equations $(1 \& 2)$ to establish differences in rental value and stock for individual property (retail space). The data table (containing the RMD variables) was then imported into GIS (QGIS) as point features. Table 1 summarises the statistical description of aspatial and spatial data variables.

Meanwhile, the spatial data i.e. the street network of York was obtained from Ordnance Survey OS (MasterMap) as a Road Centre Line (RCL). The obtained RCL was verified in the QGIS, by overlaying it on an Open Street Map layer to ascertain location precision of the data. The verified RCL data was then exported into the DepthMapX ${ }^{5}$ where the street segment configuration analysis was conducted. The street segment analysis generated spatial configuration outputs ${ }^{6}$ at global and local measures for integration and choice metrics. The local metrics were controlled at $800 \mathrm{~m}$ to represent 10 minutes' walk of retail consumers from any location within City of York network. The choice metric was normalised by dividing the local choice metric $(800 \mathrm{~m})$ by total depth metrics $(800 \mathrm{~m})$ to solve any possible paradox in choice metric outputs as a result of the street network size and pattern (Hillier et. al., 2012).

\footnotetext{
2 This was because the VOA dataset is very large data and cannot be fully opened in MS Excel.

${ }^{3} \mathrm{RMD}$ variables are computed changes in rent and stock

${ }^{4}$ In order to georeference RMD variables for geo-spatial analysis, addresses (and postcodes) of all the retail hereditaments were converted into Eastings and Northings (i.e. X and Y coordinates) using doogal software app.

${ }^{5}$ DepthMapX is a space syntax tool for spatial (street) network analysis

${ }^{6}$ The spatial configuration outputs contains syntactic values of integration and choice metrics for all the RCL/street segments.
} 
Hence, spatial configuration outputs ${ }^{7}$ (i.e. the syntactic values) of global integration, local integration (controlled at every $800 \mathrm{~m}$ ), global choice and normalised choice (NACH) were all obtained from DepthMapX. The syntactic values ${ }^{8}$ of the configured York’s street network were utilised as the Spatial Accessibility Metrics (SAM) variables for this experimental study. The SAM variables (in table text format) was then exported into QGIS as point features and for geo-spatial analysis with the aspatial data (i.e. RMD variables).

\subsection{Method of Geo-Spatial Analysis of SAM and RMD variables.}

Having exported both RMD and SAM variables into GIS (QGIS) as point features, all variables were integrated and geo-linked for spatial analysis. Due to the differences in nature (sources and functions) of RMD and SAM variables, the study adopted uniform system backdrop in analysing all variables. In doing so, spatial grid-squaring of the city space was adopted to allow consistent positioning of variables' values within the spatial grids. Each grid square holds unique ID that permits matching and linking of data into their respective grids (based on locational properties held by the data variables). As such, the city was divided into grid squares of $500 \mathrm{~m} \mathrm{X} \mathrm{500m} \mathrm{(i.e.} 0.25 \mathrm{~km}^{2}$ ) using the vector grid tool of QGIS. The 'join-attribute by location' tool in QGIS was then utilised to join all variables to their corresponding locations/positions within the defined city grids. The 'group-stat' tool of QGIS was thereafter utilised to sum and average individual variables within each grid to obtain the RMD and SAM variables per grid respectively. The average syntactic values of SAM variables are computed as the spatial accessibility index for geo-visualisation and statistical analyses in this paper.

\footnotetext{
${ }^{7}$ It is important to note that the spatial configuration outputs (that is, generated syntactic values) from DepthMapX are accompanied with spatial coordinates (Eastings and Northings). This allows the configuration outputs to be exported into QGIS for geo-spatial analysis.

${ }^{8}$ Syntactic values are generated/computed figures from DepthMapX software after street segment analysis. All the street segments (that is, RCL) within a defined a network is assigned syntactic values of integration, choice and NACH. The size of the considered network can be controlled by the user of DepthMapX, say, by 400m or $800 \mathrm{~m}$ or any other chosen distances. When such controls are implemented the software calculates syntactic values base on the controlled distance rather than computing syntactic values base on the entire street network. Calculations done based on the entire street network is called global measurements (say, global integration or global choice), while the controlled distance calculations are called local measurements (say, local integration).
} 
After grouping variables into grids, the SAM variable occupied a total of 1619 city grids (tiles), while the RMD variable occupied 152 grids. As such, number of frequency count $(\mathrm{N})^{9}$ of SAM and RMD variables were transformed from 78280 and 2875 into grids of 1619 and 152 respectively for geo-spatial analysis purpose.

To visualise spatial relationships between SAM and RMD variables, the average value (per grid) of global integration metrics was utilised as the SAM variable ${ }^{10}$. The global integration metric was styled using the natural break classification (spectra colour) in QGIS. As such, spatial accessibility index that indicates the degree of consumer movement pattern on York city space emerged in grid tiles. The accessibility index was revealed in colour pattern, with the blue tiles indicating least accessible locations and red tiles indicating highly accessible locations. Similarly, the RMD variable was also styled and classified accordingly based on level of changes in rental value and stock. Both SAM and RMD variables were then superimposed for geo-spatial visualization of relationships between them. This reveals visual relationships between the two variables that can indicate (accept or reject) the $1^{\text {st }}$ and $2^{\text {nd }}$ propositional statements of this study, whether the higher the accessibility index of location, the more the rental value (and stock) changes (or not).

However, the geo-visualisation of variables' relationship cannot suggest the level of statistical significance of SAM variables on RMD (if any). To quantify and verify the level of significance of SAM on RMD, correlation ${ }^{11}$ and multiple regression analyses was conducted using a SPSS tool. A multiple regression model was developed to determine the R-square $\left(R^{\wedge} 2\right)$ value that determines the percentage of variation that independent variables jointly account for the dependent variable. In doing so, the study adopted the RMD variable (that is, relative ${ }^{12}$ rental

\footnotetext{
${ }^{9} \mathrm{~N}$ is the frequency or counts of RMD and SAM variables as shown in the descriptive statistics Table 1.

10 This is because global integration metrics are more visually intelligible than other (correlated) SAM metrics.

${ }^{11}$ Spearman rho correlation was chosen over Pearson correlation test because variables (SAM and RMD) have been summed and grouped per grid before the correlation test. As such, a straight line relationship is not expected.

12 Relative rental value is the rent per unit square meter.
} 
value change) as dependant variable. While the SAM variables namely, global integration (GI), local integration (LI), global choice (GC) and normalised angular choice (NACH) are modelled as the independent variables. The modelled multiple regression formula is shown in equation (3) below:

$$
\mathrm{RMD}=\mathrm{a}+\mathrm{b}_{1} \mathrm{GI}+\mathrm{b}_{2} \mathrm{LI}+\mathrm{b}_{3} \mathrm{GC}+\mathrm{b}_{4} \mathrm{NACH}+\mathrm{e}
$$

Where:

$$
\begin{aligned}
& \text { RMD = Changes in retail rental value }\left(£ / \mathrm{m}^{2}\right) \\
& \mathrm{a}=\text { constant regression coefficient } \\
& \mathrm{b}_{1}=\text { coefficients of GI } \\
& \text { GI = global integration metrics (consumer to-movement) } \\
& \mathrm{b}_{2}=\text { coefficient of LI } \\
& \text { LI = local integration metrics (consumer to-movement controlled at } 800 \mathrm{~m} \text { ) } \\
& \mathrm{b}_{3}=\text { coefficient of GC } \\
& \text { GC = global choice metrics (consumer through-movement) } \\
& \mathrm{b}_{4}=\text { coefficient of NACH } \\
& \text { NACH = Normalised angular choice metrics } \\
& \text { e }=\text { error terms }
\end{aligned}
$$

The GI (global integration) is a measure of spatial configuration that estimates how close a location (street) is to all other locations within the entire network. It is known as the tomovement metric in the field of space syntax (Hillier and Hanson, 1984). The LI (local integration) is the measure of integration that has been controlled at certain metric distance (in this case, $800 \mathrm{~m}$ to represent every 10 minute walk of consumer within the city space). While the GC (global choice) is the measure of how likely a location (street) is to be pass through on all shortest routes from all locations to every other locations within a street network (Hillier et. al., 1987). The GC is referred to as the through-movement metric. Similarly, the NACH value are derived from global or local choice metrics. It is computed by dividing global choice or local choice by a corresponding total depth value of street network. In this case, a local choice (at $800 \mathrm{~m}$ ) have been divided by a total depth metric (at $800 \mathrm{~m}$ ). All these variables (GI, GC, LI 
and NACH) denote spatial accessibility measures showing accessibility scores of locations based on connectivity of streets. The syntactic values of GI, GC, LI and NACH as grouped into grids in QGIS were exported into SPSS (alongside RMD variable) for statistical analysis.

\subsection{Findings and Discussions}

\subsection{Changes in Retail Rental Value and Stock}

Table 2 shows the computed summaries of changes in retail rental value and stock between 2010 and 2017 for York (based on VOA data) using the stipulated equation 1 and 2. Table 2 indicates that there have been negative changes, both in retail rental value and retail stock within York. It reveals that there have been about 15\% and 22\% aggregate reduction in rental value and stock respectively. This is an indication that the economic performance of the City between 2008 and 2015 reflects on the performance of the retail market indicators (that is, rent and stock). This is because the retail rental value in the 2010 VOA data must have been computed based on buoyant 'pre-cash' and booming economic conditions in early 2008. Consequently, the City's retail market is yet to fully recover from the deep recession that started in the second quarter of 2008.

It is imperative to note that Table 2 has revealed the overall rent and stock changes, it does not indicate locations where changes have occurred within the city for market decision making purpose. The subsequent sections present geo-visualisation outputs of locational changes in retail rental values and stock across York.

\subsubsection{City of York retail rent (value) changes through geo-visualisation}

Locational changes in retail (property) value within York have been ranked by matching individual property change values into the established city grids for fair distribution, visualization and comprehension of rent changes across the city space. The rental value changes have been ranked into five (5) classes as high negative, low negative, no change, low positive, and high positive changes. These classes have been presented in colour grids as dark brown (high negative), light brown (low negative), black (no change), light green (low positive) 
and dark green (high positive) change as shown in Figure 2. Figure 2 shows that there have been numerous changes in retail rental value across the City of York network between 2010 and 2017. Locations (i.e. grid tiles) that have not experienced any significant rental growth or reductions are few (only 3 tiles) and are located at the periphery of the city network. Meanwhile, retail rental value changes within the city core are characterised by high changes. Figure 2 shows that the bulk of high negative changes have occurred within the city centre tiles, while many of the low positive rent changes are more widely distributed across the city. As such, there are many flourishing locations that have seen slight positive rental value growth, even though the overall rental value change for the city indicate a total $15 \%$ reduction.

\subsubsection{City of York retail stock changes through geo-visualisation}

The spatial distribution of retail stock changes across the city network of York is also presented in Figure 2. The changes in retail stock have also been classified into two (2) main classes as positive and negative changes that are represented in distinct colour columns ${ }^{13}$ revealed in Figure 2. The purple columns (4 columns) represent locations with noticeable positive stock changes within the City of York, while, the orange (single) column indicates the location where there has been noticeable reduction in retail floor space. Changes (in stock) are not extensively distributed across the city network (unlike the rental value changes). The figure reveals that there are no obvious stock changes within the city centre. The reason for scant changes in retail stock in the city centre can be linked to the inelastic nature of supply (stock) variable in a typical property market. Also, the concentration of listed and historic buildings at city centre could have hinder retail stock changes at the city core. The main implication of this result suggest that there greater potential for stock change in peripheral areas than the city core.

\footnotetext{
${ }^{13}$ Column indicates extent of stock change in that location.
} 


\subsection{Spatial Accessibility Indexes of City of York}

Spatial accessibility index of City of York was computed in DepthMapX where all syntactic values of SAM variables were obtained. These variables were exported into QGIS (from DepthMapX) for analysis ${ }^{14}$. For geo-visualisation purpose, the global integration metrics was utilised as the SAM variable in the QGIS because of it high visual intelligibility as shown in Figure 3 below. The global integration metric outputs were spatially arranged into coloured grid tiles based on its embedded syntactic values obtained from DepthMapX. Each colour represents strength (index) of locations' accessibility within the city network. The order of accessibility index is such that red and orange grids represent accessible locations, while blue and green grids indicate locations with the least accessible index. As such, the spatial accessibility index of all locations within York network emerged.

The accessibility index tiles in Figure 3 depicts the likelihood of retail consumer movement within the city's street network based on space syntax principle. The interpretation of this is that locations (tiles) in red and orange colours are the most accessible locations for retail consumers, while the green and blue tiles are locations are the least accessible locations for retail consumers. Figure 3 clearly indicates that the city core (dominated by red and orange tiles) is the most accessible part of city, while the north-western part of the city is the most segregated part of the city. This implies that locations (with high accessible index) will experience the greatest retail consumers' movement when compared with other locations within the city network.

\subsection{Spatial and Statistical Relationships between SAM and RMD variables.}

The spatial relationship between variables of RMD (i.e. rental value changes and stock changes) and spatial accessibility metrics (i.e. the global integration metrics) is obvious in the Figure 3. The figure reveals that many of the retail properties are located in places with good

\footnotetext{
${ }^{14}$ Analysis with other datasets (rent and stock) is not possible within DepthMapX.
} 
accessible indexes (i.e. red and orange tiles) since these are locations that retail consumers can have easy access to. It further indicates that both positive and negative (high) changes in rental values have occurred in locations with good accessibility index, while locations with least accessibility index have experienced slight positive and negative changes in rental value. Likewise, it shows that the large negative stock change (downward column) has occurred on one of the highly accessible tiles, while many of the positive stock changes (upward columns) are found within good accessible locations. This suggests that locations with high accessibility index are more subject to retail market changes than locations with low accessibility index. In other words, accessibility index can also contribute to volatility of retail market indicators. However, because locations with no rental value changes are also situated on good accessibility tiles, it can be contended that the changes in RMD variables and SAM index are moving towards the same relative direction but not at a constant rate. The spatial relationship between RMD and SAM variables, thus, indicates that a monotonic ${ }^{15}$ relationship exist more than a linear relationship. Hence, Spearman's correlation coefficient is more appropriate in testing relationship between RMD and SAM. Table 3 shows the matrix output of Spearman correlation test between all the SAM and RMD variables.

Table 3 affirms that there are spatial relationships between SAM (global integration metrics) and RMD (changes in rental value and stock) variables. It reveals that all variables are significantly correlated at 0.01 significant level. The global choice metric is the least significant variable to both changes in rental value and stock with coefficients of 0.065 and 0.271 respectively. While the global integration metric shows the highest significance to both changes in rental value and stock at 0.086 and 0.362 coefficients respectively. The retail stock change variable shows a stronger relationship with the SAM variables than the rental value changes,

\footnotetext{
${ }^{15}$ In monotonic relationship, the variables tend to move in the same relative direction, but not necessarily at a constant rate.
} 
as initially suggested in the spatial relationship output of Figure 5 (above). Nevertheless, changes in retail rental value within York have shown positive and significant correlation with the SAM variable. Thus, the study affirms 'the higher the spatial accessibility index of City of York, the more changes in both retail rental value and stock within City of York network'.

This implies that spatial accessibility measures of space syntax (despite not considering socioeconomic and other factors) still influence and relate with RMD variable within the City of York. The study further explored the potential to establish the percentage of the variance in RMD (changes in relative rental value) variable that the SAM variables collectively explain. This was done by exploring the R-square of the developed multiple regression model in equation 3. Table 4 reveals the regression results (estimates) and R-square value between RMD and SAM variables.

Table 4 shows the output model of equation 3 that seeks to estimate the percentage of RMD variability that SAM variables (namely, global integration, local integration at $800 \mathrm{~m}$, global choice and normalised choice) jointly explain. The empirical result presented in the result table reveals that $\mathrm{NACH}$ metrics, local integration metrics and global integration metrics are significant determinants of changes in retail rental values in York. This implies that computation of through movement (that is, choice metric) at global city scale is irrelevant to changes in York retail rent as previously suggested in the Spearman correlation result. Furthermore, in consideration of the entire variables fitted into the model (equation 3), the result table reveals that the R-square is 0.221 . The interpretation of this is that the SAM variables jointly account for $22.1 \%$ of the variation in RMD within the City of York. In other words, $22 \%$ of RMD variability are explained by the spatial accessibility index computed based on space syntax theory. Embedding the regression coefficient model into equation (3) implies that;

$\mathrm{RMD}=98.233+0.002(\mathrm{GI})+0.026(\mathrm{LI})+0.000(\mathrm{GC})+1.831(\mathrm{NACH})$ 
Whilst the study does not aim to establish the fitness of the above regression model, it does demonstrates that consumer to-movement (GI and LI) variables at global and local scales are significant SAM variables on RMD variable. The study recognises that there are other spatial configuration metrics (such as, total depth, node counts, other local controlled metrics of choice and integration) that can be fitted into the model to enhance R-squared result and consequently the model. It is important to state that the developed model has only incorporated integration and choice at local (controlled 800m) and global scales to represent retail consumer movement index on City of York network. Similarly, there are other possible factors asides SAM variables that can contributes to explaining RMD variability within the sampled City of York.

\subsection{Conclusions and Recommendations}

Analyses conducted in this study reveal there have been positive and negative changes in retail rental value and stock variables across different locations within City of York between 2010 and 2017. Many of the changes in retail rental values are widely distributed in an uneven pattern across the city, while changes in stock have been confined to limited locations within the city network. The aggregation of changes are negative for both changes in retail rental value and stock. The study further established that there are spatial and statistical relationships between spatial configuration outputs of SAM variables and the RMD variables (as measured by changes in retail rental value and stock). The higher the SAM values, the more the changes (positive and negative) in the RMD variables. The developed regression model in the study suggested that the SAM variables (NACH, global choice, global integration and local integration metrics) jointly account for 22\% of RMD variability within City of York network, even though, the global choice metric is the least significant variable of SAM on RMD.

This study recommends application of space syntax techniques and tools to retail property markets to assist stakeholders (such as, retailers, retail property owners, city planners, and real property developers) when making spatial related decisions within any given city. Spatial 
configuration outputs that compute accessibility index of streets network, should be utilised as an effective tool in making varieties of decisions, for example, site selection for retail development, site suitability for retail store locations, downsizing and or closing of retail store branches, changing use of property space, among other retail property development, investment and occupation decision tasks. Whilst this research focuses on retail property market within York's street network, the developed research methods are applicable on any given city space and property types (including, residential, offices and industrial) assuming similar data exists. The study recommends applying this research method across other city space network and property types to further explore relevance of spatial configuration outputs on real property markets.

Finally, the study recommends that the space syntax society (specifically, the software developers) take additional steps in establishing a straight forward tools that is capable of integrating socio-economic datasets into DepthMapX. Such steps will further broaden applications of space syntax in property and city space analyses. 


\section{References}

Adebayo, A., Greenhalgh, P., and Muldoon-Smith, K., (2017) 'A taxonomy of data and software tools for geo-spatial analysis of town and city centre retail space', The Terrier Journal of Association of Chief Estates Surveyors Vol. 22 No.3 pp. 47-50.

Astbury, G., and Thurstain-Goodwin, M., (2014) 'Measuring the impact of out-of-town retail development on town centre retail property in England and Wales’ Applied Spatial Analysis. Vol. 7 No. 4, pp. 301-316.

Baradaran, S., and Ramjerdi, F., (2001) 'Performance of Accessibility measures in Europe'. Journal of Transportation and Statistics, December, pp.12-17

Batty, M. (2008) 'Cities as complex systems: scaling, interactions, networks, dynamics and urban morphologies’, working paper [131]. UCL London. 20 February

Brown, S. (1991) 'Retail location theory: retrospect and prospect', Irish Marketing Review, Vol.5 No.2, pp. 52 - 60 .

Chiaradia, A., Hillier, B., Barnes, Y., Schwander, C. Koch, D Marcus, L., and Steen, J. (2009) 'Residential property value patterns in London: space syntax spatial analysis', paper presented at $7^{\text {th }}$ International Space Syntax Symposium, 29 May - 1 June, Stockhom, Sweden.

Colwell, P.F., and Jackson, C. (2004) 'Modelling rental change across key retail investment market in Britain', Journal of property investment and finance Vol. 22 No. 5, pp.354 -385 Dalton, N.S., and Dalton R.C. (2009) 'The theory of natural movement and its application to the simulation of Mobile Ad Hoc Network (MANET)' CNSR'07

Deloitte (2018) 'Global powers of retailing- transformative change, reinvigorated commerce’, available at; https://www2.deloitte.com/content/dam/Deloitte/global/Documents/consumerindustrial-products/cip-2018-global-powers-retailing.pdf (accessed: 25 September 2018) 
Dixon, T. J., (2007) 'The role of retailing in urban regeneration', Local Economy, Vol. 20 No.2, pp.168-182

Dunse, N. Jones, C. and White, M. (2010) 'Valuation accuracy and spatial variations in the efficiency of the property market', Journal of European Real Estate Research Vol.3 No. 1 pp.24-45.

Evans, A., W., (2008) 'Economics, real estate, and the supply of land' Wiley-Blackwell, Oxford.

Figueiredo, L., (2015) 'A unified graph model for line and segment maps,'presented at proceedings of $10^{\text {th }}$ International Space Syntax Symposium $13^{\text {th }}-17^{\text {th }}$ July, London pp.146:111

Giannopoulou, M., Vavatsikos, A. P. and Lykostratis, K. (2016) 'A process for defining relations between urban integration and residential market prices', Journal of Social and Behavioral Sciences, Vol. 223 No. 2 pp. 153-159.

Greenhalgh, P., (2008) ‘An examination of business occupier relocation decision making: distinguishing small and large firm behaviour’. Journal of Property Research, Vol. 25 No. 2 pp.107 - 126.

Greenhalgh, P., \& King, H., (2013) Developing an indicator of property market resilience investigating the potential of GIS to analyse business occupier displacement and property market filtering: a case study of Tyne and Wear. Urban Studies, Vol. 50 No.2. pp. 372-390 Guers, K.T., \& van Wee, B., (2004) ‘Accessibility evaluation of land-use and transport strategies: review and research direction’ Journal of Transport Geography Vol. 12 No. 2, pp.127 -140

Hendershott, P., Macgregor, B. and White, M. (2002) Explaining Real Commercial Rent Using an Error correction model with panel data. Journal of Real Estate Finance and Economics. Vol. 24 No.1, pp.59 -87 
Hillier, B., and Hanson, J., (1984) 'The social logic of space. Cambridge UK.

Hillier, B., Burdett, R., Peponis, J., Penn, A. (1987), Creating Life: Or, Does Architecture

Determine Anything? Architecture et Comportement/Architecture and Behaviour, Vol 3 No.3 pp.233 - 250 .

Hillier, B., Penn, A., Hanson, J., Grajewski, T., and Wu, J. (1993) 'Natural movement: or, configuration and attraction in urban pedestrian movement. Environment and Planning A Vol. 20 No.1, pp. 29-66.

Hillier, B. (1996), 'Space is the Machine: A Configurational Theory of Architecture'. Space Syntax London, pp. 55-78

Hillier, B., Yang, T., Turner, A., (2012) 'Normalising least angle choice in Depthmap and how it opens up new perspectives on the global and local analysis of city space' Journal of Space Syntax, Vol. 3 No. 2 pp. 155-193

Huff, D.L. (1962).'A note on the limitations of interurban gravity models'. Land Economics, Vol. 38 N0. 1, pp.64-66.

Ingrid, N. (2006) 'The role and behaviour of commercial property investors and developers in French urban regeneration: The experience of the Paris region’ Urban studies, Vol. 43 No. 9 pp. 1511-1535.

Jeong, S. K. and Ban, Y. U. (2011) ‘Computational algorithms to evaluate design solutions using Space Syntax’, Computer-Aided Design, Vol. 43 No. 6, pp. 664-676.

Jiang, B., Claramunt, C., and Klaqvist, B. (2000). An integration of space syntax into GIS for modelling urban spaces. International Journal of Applied Earth Observation and Geoinformatics Vol. 2 No. 3, pp. 161 -171.

Jie, C., Jianhua, N., Changbai, Xi, Siqian, L., Jiechen, W., (2017) 'Determining intra-urban spatial accessibility disparities in multimodal public transport networks,' Journal of Transport Geography, Vol. 65, pp.123-133. 
Kolovou, I., \& Gil, J., Karimi, K., Law, S., \& Versluis, L., (2017) 'Road Centre Line Simplification Principles for Angular,' presented at proceedings of $11^{\text {th }}$ Space Syntax Symposium, 163, Lisbon pp. 1-16.

Law, S., Stonor, T., \& Lingawi, S. (2013). 'Urban value: Measuring the impact of spatial layout design using space syntax’. Presented in Proceedings of the Ninth International Space Syntax Symposium. Seoul pp.1-5

Liang, J. and Wilhelmsson, M. (2011) 'The value of retail rents with regression models: a case study of Shanghai’ Journal of property Investment \& Finance’ Vol.29 No.6 pp. 630-643 Muldoon-Smith, K., Greenhalgh, P., Dalton, R., Alvanides, S., King, H., \& Sparkes, B. (2015) 'Urban transactions: Investigating the relationship between spatial preference and spatial configuration in the city of Leeds', presented in 10th International Space Syntax Symposium, 2015. London pp. 94-114.

Nanthakumara, N., Watkins, C., and Orr, A. (2000) 'Understanding property market dynamics: insights from modelling the supply-side adjustment mechanism’ Environment and Planning A, Vol. 32 No. 4, pp. 655-671.

Nsibande, M., Boshoff, D.G.B, (2017) ‘An investigation into the investment decision-making practices of South African institutional investors: A focus on retail property' Journal of Property Management, Vol. 35, No. 1, pp.67-88.

ONS (2017) 'Economic statistics transformation programme: enhanced financial accounts (UK flow of funds) - A flow of funds approach to understanding financial crises', available at:https://www.ons.gov.uk/economy/nationalaccounts/uksectoraccounts/articles/economicstat isticstransformationprogramme/enhancedfinancialaccountsukflowoffundsaflowoffundsapproa chtounderstandingfinancialcrises (accessed 12 November 2017).

Peponis, J., Ross, C. and Rashid, M. (1997) 'The structure of urban space, movement and copresence: The case of Atlanta', Geoforum, Vol. 28 No. 3-4, pp. 341-358. 
Peponis, J., Bafna, S., and Zhang, Z. (2008). The connectivity of streets: Reach and directional distance. Environment and Planning B: Planning and Design, Vol. 35 No. 5, pp. 881- 901.

Ratti, C. (2004) 'Space syntax: Some inconsistencies’, Environment and Planning B:

Planning and Design, Vol. 31No.4, pp. 487-499.

Reggiani, A. (2012) ‘Accessibility, connectivity and resilience in complex networks,' in Gueurs K.T., Krizek, K.J., Reggiani, A. (Eds.), Accessibility analysis and transport Planning: an introduction, Cheltenham, Edward Elgar, pp.15-37.

Rhodes, C. \& Brien P. (2017). 'The retail industry: statistics and policy', available at http://researchbriefings.files.parliament.uk/documents/SN06186/SN06186.pdf. (accessed 25

November, 2017)

RICS (2017) ‘RICS Valuation -Global Standards’ July, VPGA 8. P.133

Stonor, T, (2008) 'Rethinking urban spatial barricades' available at:

https://search.proquest.com/docview/229905578?rfr_id=info\%3Axri\%2Fsid\%3Aprimo

(accessed 16 October 2016)

Tsolacos, S., and Mcgough, T., (1999) 'Rational expectations, uncertainty and cyclical activity in the British office market.' Urban Studies, Vol. 36 No. 7, pp.1137 -1149

Turner A. (2007), ‘From axial to road-centre lines: a new representation for space syntax and a new model of route choice for transport network analysis', Environment and Planning and Design, Vol. 34 No.2. pp. 539-555.

Vitalii, K. and Lena, H. (2016) ‘The Value of Location: Spatial Analysis of Urban’, Journal of Management and Applied Science, Vol. 2 No.11, pp. 143-146.

VOA (2017) 'Non-domestic business property rates’ available at:

https://www.gov.uk/topic/local-government/business-rates (accessed 25 June 2017) 
Wyatt, P., (1996) 'The development of a property information system for valuation using a geographical information system (GIS)', Journal of Property Research, Vol 13 No. 4, 317336. 


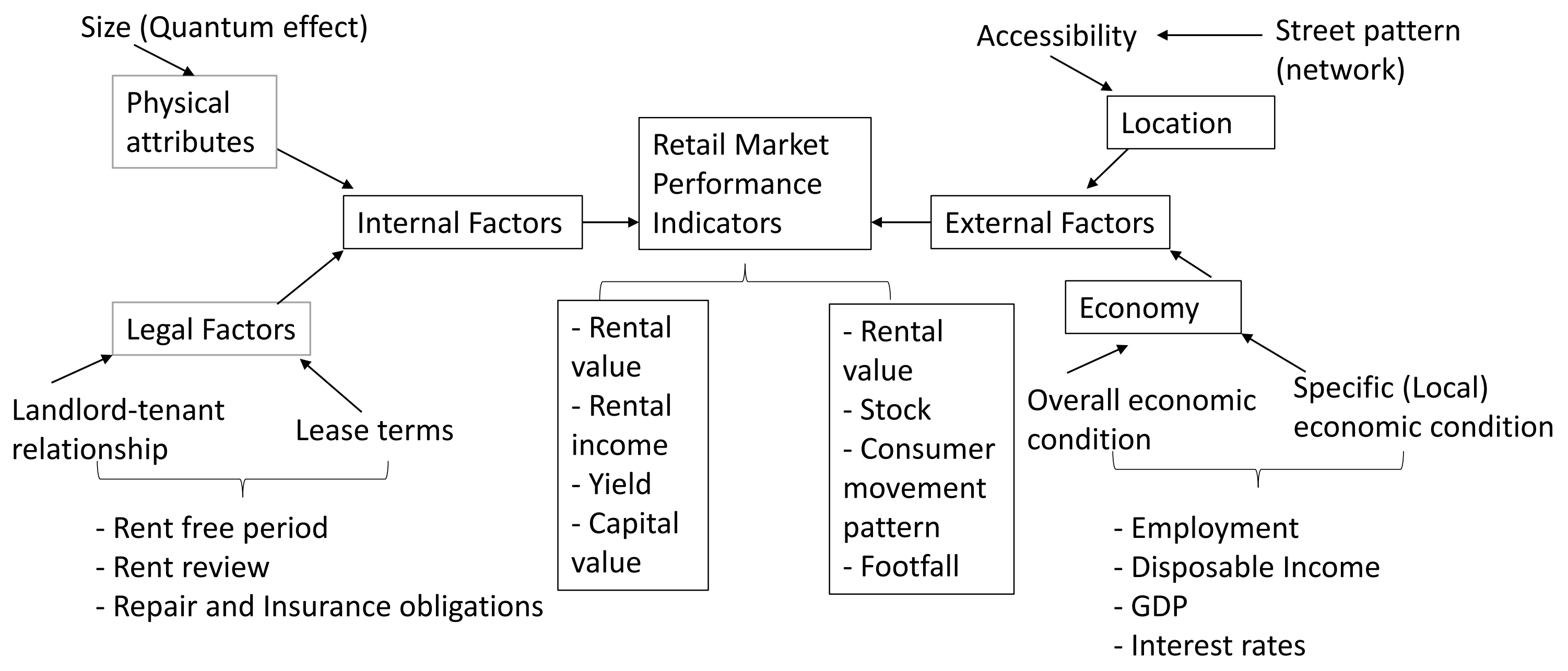

Adapted from: Wyatt (1996) 
Figure 2: Distribution of RMD variables (changes in retail stock and rental value) for City of York

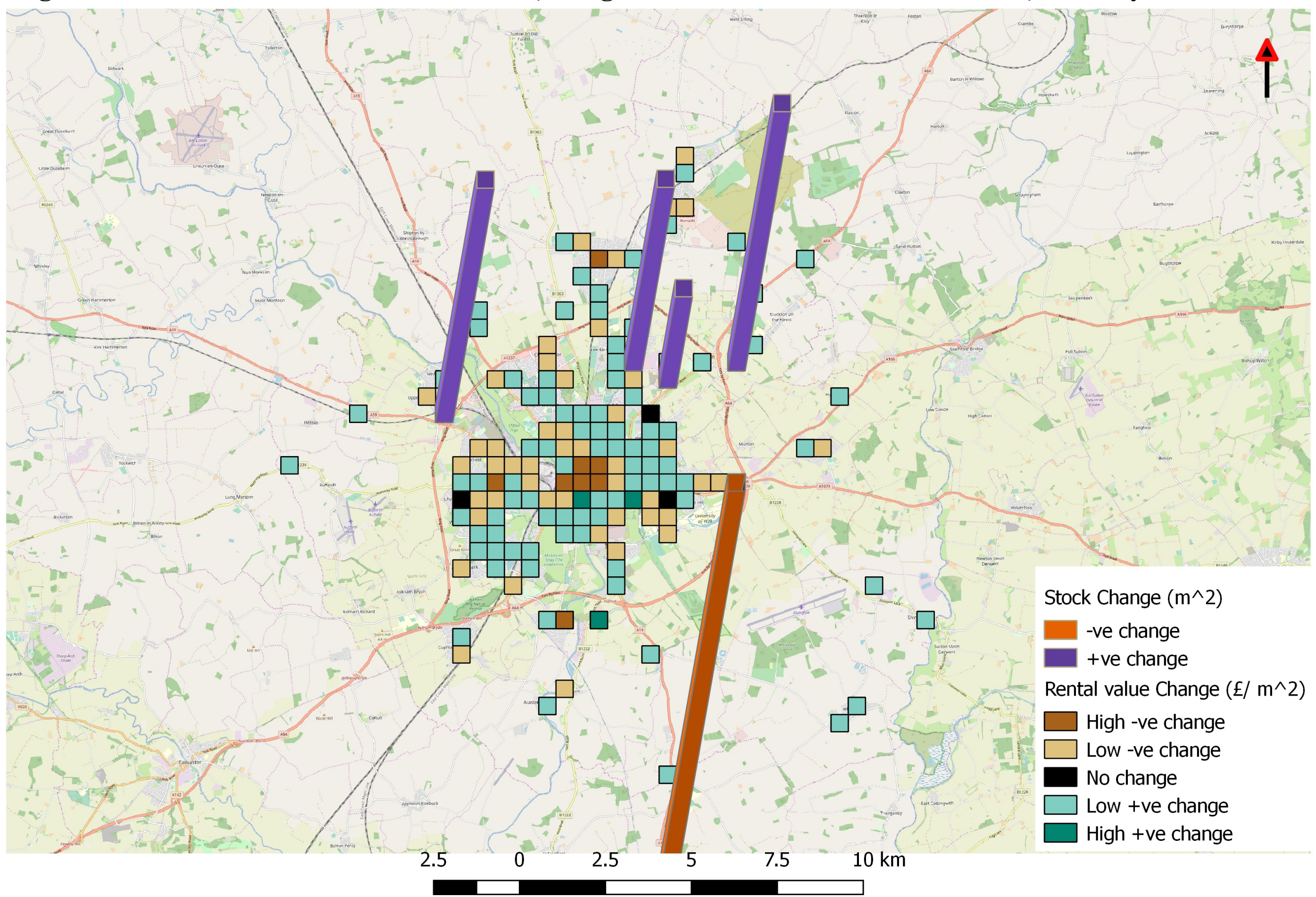




\section{Figure 3: Spatial Acessibility and Changes in Retail Stock \& Rent (RMD) for City of York}

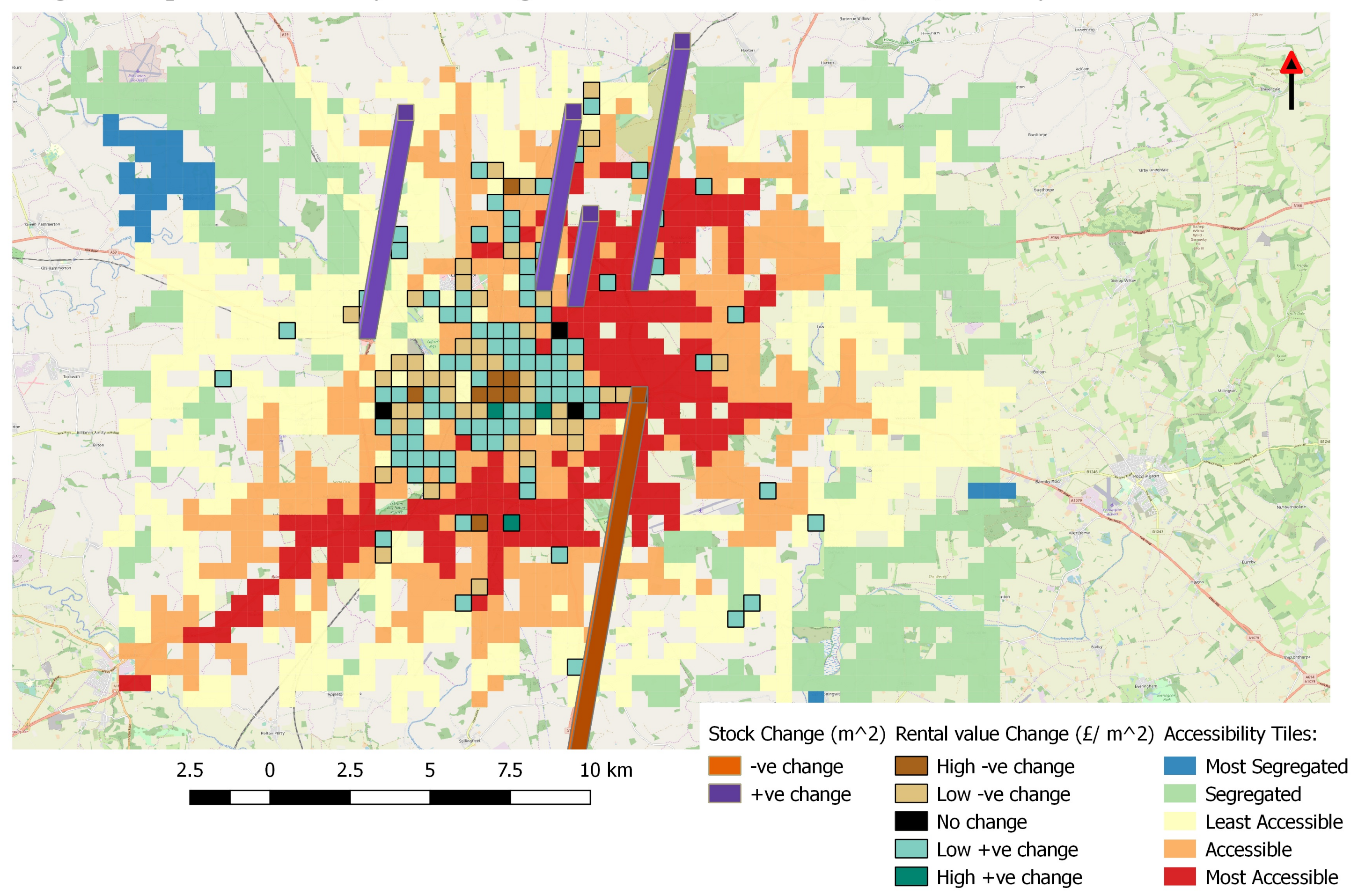


Table 1: Descriptive Statistics for RMD and SAM Variables (City of York)

\begin{tabular}{|l|rrrr|rrrr|}
\hline & \multicolumn{7}{|c|}{ RMD variables } & \multicolumn{4}{|c|}{ SAM variables } \\
Basic Statistics & 2010 Rent & 2010 Stock & 2017 Rent & 2017 Stock & GI & LI & GC & NACH \\
\hline N & 2875 & 2875 & 2875 & 2875 & 78280 & 78280 & 78280 & 78280 \\
Mean & 33630.08 & 195.72856 & 29243.86 & 159.53325 & 3127 & 95.78 & $2.46 \mathrm{E}+07$ & 3.3 \\
Minimum & 0 & 1 & 0 & 1 & 7.43 & 7.43 & 0 & 0.59 \\
Maximum & 1160000 & 7822.96 & 457500 & 7652.7 & 4960 & 693.77 & $1.45 \mathrm{E}+09$ & 5.24 \\
Std. Deviation & 60562.27 & 499.20005 & 46267.784 & 406.84291 & 646.4 & 53.08 & $8.19 \mathrm{E}+07$ & 1.15 \\
Median & 15750 & 91.88 & 13750 & 72.7 & & & & \\
Variance & $3.67 \mathrm{E}+09$ & 249200.69 & $2.141 \mathrm{E}+09$ & 165521.15 & & & & \\
Skewness & 7.353 & 11.025 & 3.804 & 12.682 & & & & \\
Std. Error of Skewness & 0.046 & 0.046 & 0.046 & 0.046 & & & & \\
Kurtosis & 97.288 & 140.719 & 20.194 & 200.978 & & & & \\
Std. Error of Kurtosis & 0.091 & 0.091 & 0.091 & 0.091 & & & & \\
\hline
\end{tabular}

RMD variables is adapted from VOA (2017) https://voaratinglists.blob.core.windows.net/html/rlidata.htm SAM variables are computed RCL outputs from DepthMapX (2018) 
Table 2: Computed Changes in retail rent and stock for York

\begin{tabular}{|c|c|c|}
\hline Variable & Value & Approximate value \\
\hline$\overline{\sum 2017 \text { rent }(£)}$ & 84078375.00 & $84,000,000.00$ \\
\hline$\sum 2010$ rent $(£)$ & 96690035.00 & $97,000,000.00$ \\
\hline Change rent $(£)$ & $-12,611,660.00$ & $-13,000,000.00$ \\
\hline Change rent $(\%)$ & $-15 \%$ & $-15 \%$ \\
\hline$\sum 2017$ stock $\left(\mathrm{m}^{\wedge} 2\right)$ & 458682.19 & 460,000 \\
\hline$\sum 2010$ stock $\left(\mathrm{m}^{\wedge} 2\right)$ & 562743.09 & 570,000 \\
\hline Change stock $\left(\mathrm{m}^{\wedge} 2\right)$ & -104060.90 & $-100,000$ \\
\hline Change stock (\%) & $-22.68 \%$ & $-22 \%$ \\
\hline
\end{tabular}

Source: Adapted from VOA (2017) 
Table 3: Spearman's rho Corrrelation Coefficient

NACH Global choice Global Integration Local Integration Change_RV Change_stock

\begin{tabular}{|c|c|c|c|c|c|}
\hline $\mathrm{NACH}$ & $.685 * *$ & $.962 * *$ & $.973 * *$ & $.080 * *$ & $.355^{* *}$ \\
\hline Global choice & 1 & $.726 * *$ & $.699 * *$ & $.065^{* *}$ & $.271 * *$ \\
\hline Global Integration & & 1 & $.943 * *$ & $.086^{* *}$ & $.362 * *$ \\
\hline Local Integration & & & 1 & $.080 * *$ & $.360 * *$ \\
\hline Change_RV & & & & 1 & $.171 * *$ \\
\hline
\end{tabular}

** Correlation is significant at the 0.01 level (2-tailed).

$\mathrm{N}=1622$ 
Table 4: Regression results (estimates) between RMD and SAM variables

\begin{tabular}{lcccc}
\hline Variables & Regression Coefficient & Beta Coefficient & t-value & sig. \\
\hline Constant & 98.233 & & -0.712 & 0.477 \\
NACH & 1.831 & -0.739 & -4.846 & $0.001^{*}$ \\
Global Choice & 0.000 & -0.080 & -2.938 & 0.103 \\
Local Integration & 0.026 & 0.291 & 3.732 & $0.000^{*}$ \\
Global Integration & 0.002 & 0.751 & 5.228 & $0.000^{*}$ \\
\hline R
\end{tabular}

$\mathrm{R}=.470$

$\mathrm{R}^{\wedge} 2=0.221$

$\mathrm{R}^{\wedge} 2$ adjusted $=0.200$

Std error $=2973.032$

$\mathrm{N}=152$ 